\title{
Mortality of SARS-CoV-2 in patients with lower level education and poor socioeconomic status in a developing country
}

\author{
Marcio José Concepción Zavaleta ${ }^{1}$, Julia Cristina Coronado Arroyo ${ }^{2}$, Francisca Elena \\ Zavaleta Gutiérrez ${ }^{3}$, and Luis Alberto Concepción Urteaga ${ }^{4}$ \\ ${ }^{1}$ Level IV Hospital Guillermo Almenara Irigoyen \\ ${ }^{2}$ National Hospital Edgardo Rebagliati Martins \\ ${ }^{3}$ Belen Hospital of Trujillo \\ ${ }^{4}$ Universidad Nacional de Trujillo Facultad de Medicina
}

July 8, 2020

Dear Editor:

Severe acute respiratory syndrome coronavirus 2 (SARS-CoV-2) is a highly contagious infectious disease of international concern that spreads mainly from person to person through respiratory droplets. ${ }^{1,2}$ As of July 2020, outbreaks are being reported in China, the country where the pandemic started and in which it was thought initially to be controlled. ${ }^{3}$ In a similar manner, in other countries like Peru, instead of being controlled, the pandemic is increasing in severity and prevalence. Until July 6, 2020, > 11 million cases had been confirmed across the world, with $>300000$ cases and $>10000$ deaths in Peru. ${ }^{4}$

It is necessary to adopt intentional and thoughtful acts to control the SARS-CoV-2 pandemic. Social distancing measures, minimization of personal contacts, and hand sanitization are effective in limiting the community spread of SARS-CoV-2. ${ }^{1}$ However, there are social variables that cannot be controlled in Peru, such as lower level education and poor socioeconomic status in a significant percentage of the population ${ }^{5}$; these factors are related to the morbidity and mortality attributable to COVID 19 infection. $^{6}$

The Centers for Disease Control and Prevention (CDC) describes a list of risk factors for SARS-CoV-2 infection that includes poverty and crowding ${ }^{2}$. Likewise, a UK-based study investigated the role of ethnicity and socioeconomic position in the development of SARS-CoV-2 infection. They found that socioeconomic deprivation and lack of qualifications were consistently associated with a higher risk of confirmed infection ${ }^{6}$. Further, reports have shown higher mortality from infectious diseases in patients with a low level of education ${ }^{7}$. To our knowledge, no studies in Peru have investigated the relationships among the level of education, the socioeconomic status, SARS-CoV-2 infection, and the severity and mortality of the infection, however, statistical findings show a higher frequency of low educational level in people who have died as a result of infection by the virus SARS-CoV-2(Figure 1)

Health outcomes are closely related to the educational level. Some types of health behaviors, such as smoking, heavy alcohol drinking, physical inactivity, and unhealthy diet, are expected to mediate the impact of educational level on the incidence of non-communicable diseases ${ }^{8}$. It is also remarkable that the total prevalence of overweight and obesity in Peru is $60.2 \%$ in the total population ${ }^{9}$. Moreover, lower levels of education are related to higher incidence and prevalence of cardiovascular and cerebrovascular disease, cancer, diabetes, hypertension, and chronic respiratory disease ${ }^{8}$. Patients with these diseases are at an increased risk of severe illness from COVID-19 because of lower levels of immune cells and high cytokine levels in the body fluids ${ }^{1,2}$. 
Educational inequalities in these chronic diseases are mediated by the patient's socioeconomic status. As expected, low income level and unstable job status that may be linked to low educational level are reasonably predicted to raise the risk of these diseases ${ }^{8}$. In Peru, $>1 / 3^{\text {rd }}$ of the population lives in the urban capital, Lima; however, a substantial population still lives in rural areas, with limited access to medical care, chronic disease treatment, and education. These rural residents are often poorer and less educated than their urban counterparts ${ }^{10}$.

Another important factor that influences the characteristics of the COVID-19 pandemic is population density; ${ }^{1}$ the population density in Peru is 25 people per square kilometer, with a substantial density in the rural population ${ }^{11}$. Some studies have shown a significant positive linear relationship of population density with number of cases, deaths, and case-fatality rate of SARS-CoV-2. Moreover, there is a significant positive correlation between the number of medical supplies and population density, suggesting that this variable and the lack of medical equipment are key factors that explain the morbidity and mortality of COVID- $19^{12}$.

By $2019,87 \%$ of Peruvians had health insurance coverage; ${ }^{13}$ however, the quality of health services in the hospitals of the Ministry of Health, in regular situations, is perceived to be low ${ }^{14}$. The pandemic hit Peru when the country was in the process of improving health services and denoted significant deficiencies across the health system, revealing the need for urgent actions. The lack of equipment, supplies, and medications translates into poor quality of care and plays an important role in the health consequences of the COVID-19 pandemic.

In conclusion, we highlight the importance of eliminating the inequality in the coverage of health services and continuing to improve the education for the Peruvian population to control social factors and enable optimal management of the COVID-19 pandemic.

\section{Conflict of interest}

The authors declare no conflict of interest in this publication.

Figure 1. Mortality from SARS-CoV-2 according to level education in peruvian population. Source: National Death Computer System. Ministry of Health. Peru. 2020

\section{References}

1. Lakshmi PS, Suresh M. Factors influencing the epidemiological characteristics of pandemic COVID 19: A TISM approach. Int J Healthc Manag. 2020;13(2):89-98.

2. Coronavirus Disease 2019 (COVID-19). Centers for Disease Control and Prevention. https://www.cdc.gov/coronavirus/2019-ncov/covid-data/investigations-discovery/assessing-riskfactors.html. Published 2020. Accessed July 5, 2020.

3. Liu J, Huang J, Xiang D. Large SARS-CoV-2 Outbreak Caused by Asymptomatic Traveler, China. Emerging Infect Dis. 2020;29(9).

4. COVID-19 Updates for Perú. Health Bridges International. https://www.hbint.org/covid-19-updatesfor-peruacute.html. Published 2020. Accessed July 7, 2020.

5. Mendoza A. Inequality In Peru: Reality And Risks. Lima, Perú; 2020:5-9. https://peru.oxfam.org/en/node/195. Accessed July 5, 2020.

6. Niedzwiedz C, O'Donnell C, Jani B et al. Ethnic and socioeconomic differences in SARS-CoV-2 infection: prospective cohort study using UK Biobank. BMC Med. 2020;18(1):1-9.

7. Regidor E. Educational level and mortality from infectious diseases. Journal of Epidemiology \& Community Health. 2002;56(9):682-683.

8. Oshio T, Kan M. Educational level as a predictor of the incidences of non-communicable diseases among middle-aged Japanese: a hazards-model analysis. BMC Public Health. 2019;19(1):1-9.

9. Pajuelo RJ, Torres AL, Agüero ZR, Bernui LI. Overwight, obesity and abdominal obesity in the adult population of Peru. An Facc Med. 2019;80(1):21-27 
10. Dmytraczenko TG, Almeida G. Toward Universal Health Coverage and Equity in Latin America and the Caribbean: Evidence from Selected Countries. Washington, DC: World Bank; 2015

11. Peru Demographics 2020 (Population, Age, Sex, Trends) - Worldometer. Worldometers.info. $\quad$ https://www.worldometers.info/demographics/perudemographics/\#: :text=The\%202019\%20population\%20density\%20in,of\%201\%2C280\%2C000\%20Km2\%20(494\%2C21 Published 2020. Accessed July 5, 2020.

12. Ilardi A, Chieffi S, Iavarone A, Ilardi C. SARS-CoV-2 in Italy: Population Density correlates with Morbidity and Mortality. Jpn J Infect Dis. 2020:3-6

13. De Habich M. Leadership Politics and the Evolution of the Universal Health Insurance Reform in Peru. Health Systems \& Reform. 2019;5(3):244-249.

14. Soto A. Barriers to effective care in the referral hospitals of Peru's Ministry of Health: serving patients in the 21st century with 20th century resources. Rev Peru Med Exp Salud Publica. 2019;36(2):304.

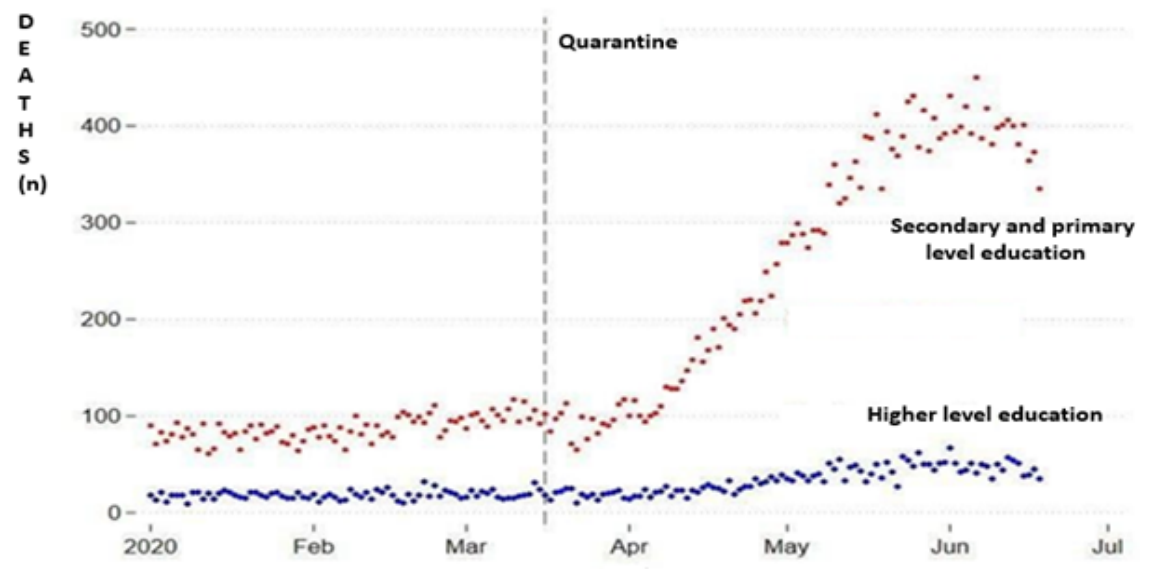

